Thomas M. Dousa - University of Illinois, Urbana-Champaign

\title{
Evolutionary Order in the Classification Theories of C. A. Cutter \& E. C. Richardson: Its Nature and Limits
}

\begin{abstract}
In recent years, evolutionary order has been used as the favored mode of determining class sequence by classificationists using integrative levels as a theoretical framework for classification design. Although current advocates of evolutionary order are based in Europe, use of the concept in library and information science (LIS) can be traced back to two North American pioneers in classification theory, C. A. Cutter (1837-1903) and E. C. Richardson (1860-1939). Working in the heyday of evolutionism and influenced by the developmental classifications of the sciences of Auguste Comte and Herbert Spencer, Cutter and Richardson introduced evolutionary order as an explicit principle into LIS classification theory, defining it as encompassing a conceptual progression from the general to the specific, the simple to the complex, and the past to the present. This idea proved influential, being appropriated by later theoreticians like H. E. Bliss; it also reinforced the realist tendency of early LIS classification theory. However, for Cutter and Richardson, application of evolutionary order to bibliothecal classifications proved problematic. Cutter applied the concept inconsistently; Richardson viewed it as theoretically ideal, but subject to so many exceptions for pragmatic reasons that it could not be attained in practice. Cutter's and Richardson's use of evolutionary order reveals the tension between enunciating a principle of classificatory ordering in theory and applying it in practice.
\end{abstract}

\section{Introduction: The Principle of Evolutionary Order in Knowledge Organization}

An important element in the design of classification schemes is determining the sequence in which to order classes within an array, be it the array of main classes that forms the structural backbone of a classification or arrays located further down in the classificatory hierarchy. Classificationists have a number of different principles for the ordering of classes in array at their disposal (Ranganathan 1967, §§ FA-FJ; Richardson 1901, 8-11): one that has enjoyed an especially high profile within discussions of knowledge organization $(\mathrm{KO})$ theory in recent years has been that of evolutionary order. Ongoing interest in evolutionary order is due to research efforts at applying the theory of integrative levels to general faceted classifications. This theory, which rests on the fundamental premise that "the world of entities evolves from the simple towards the complex by an accumulation of properties or influences from the environment"- a process resulting in progressively higher levels of organization (Foskett 1978, 204; cf. Gnoli \& Poli 2004, 153-155) - , was first introduced into library and information science (LIS) in the late 1950s by members of the English-based Classification Research Group (CRG), who took it as the theoretical basis for research into developing a new general faceted classification scheme (Spiteri 1995). Since the early 2000s, KO interest in integrative levels has received fresh impetus from the Integrative Level Classification (ILC) project in Italy, which is currently using the theory to experiment with a new, "freely faceted", phenomenon-based general classification (Gnoli 2008; 2008-). 
Evolutionary order as a fundamental ordering principle for classification, then, has found its most recent adherents in Europe. However, its roots within LIS extend back to North America. As Broughton (2008, 49-50) has observed, the idea of integrative levels is compatible with the principle of "gradation by speciality" enunciated by the American classification theorist Henry Evelyn Bliss. According to Bliss (1929, 217, 216), the optimal order for disciplines within a bibliothecal classification is one in which they "are arranged in serial order from the most general to the most special", there being a "correlation between generality and simplicity, and between speciality and complexity". Bliss adopted this principle, which ultimately derives from the developmental classifications of sciences created by Comte and Spencer (see the following section), as the basis for arranging the main classes in his own classification scheme and it has been retained by the editors of the faceted second edition of the Bliss Bibliographical Classification (BC2) (Mills \& Broughton, 1977, 36-37, § 5.5; Gnoli 2006, 139-140). However, even before Bliss, the topic of evolutionary order had been treated by two important pioneers of the library profession in the United States: Charles Ammi Cutter (1837-1903), influential theoretician of the dictionary catalog and the creator of the Expansive Classification, and Ernest Cushing Richardson (1860-1939), the author of the first monographic treatment of library classification theory (Maltby 1975, 57).

In this paper, I examine Cutter's and Richardson's ideas about what evolutionary order is and their prescriptions for how it is to be used within a knowledge-based bibliothecal classification. My motivation in doing so is both historical and theoretical. Cutter and Richardson were not, strictly speaking, the first persons to deploy evolutionary order for organizing bibliographical materials: they were, however, the first library theorists to advocate the concept explicitly in terms of evolutionary theory and to establish it firmly within LIS classificatory discourse. ${ }^{1}$ By viewing their arguments within the intellectual context of their time, we can gain a greater appreciation for the historical contingencies that brought about the implantation of an important and enduring idea into LIS classification theory. A close examination of Cutter's and Richardson's ideas about evolution and its role in classificatory ordering is also worthwhile from a theoretical point of view. On one hand,

1 The French bookseller and bibliographer Romain Merlin (1793-1876) had developed, in the 1840s, a bibliographic classification whose general structure was based on what we today recognize as principles of evolutionary order and submitted it as a model for American libraries at the American Librarians' Convention held in New York in 1853 (Merlin 1915 [1854]) - a proposal that Richardson (1901, pp. 183-184) characterized as "the first library plea for an evolutionary system of classification for books". Merlin did not, however, invoke "evolution" expressis verbis in his exposition of his system - he wrote about a decade before the term (and idea) began to achieve prominence in the Unites States - and his proposal did not find a receptive audience among his contemporaries either in the United States or elsewhere in the anglophone world (cf., e.g., Edwards 1859, vol. 2, 801-802). Later, in the early 1860s, the geologist and librarian J. S. Lesley (1819-1903) had created a classification for the library of the American Philosophical Society, whose main outline was structured in accordance to evolutionary order (Lesley 1863, 417): however, like Merlin, he did not explicitly associate his classification with the term "evolution" and his system appears to have had no impact upon his contemporaries (cf. LaMontagne 1952, 22, 24). Merlin's and Lesley's "implicitly" evolutionary schemes merit closer comparison with the "explicitly" evolutionary ones of Cutter and Richardson, but that is a topic for another paper. 
it gives us the opportunity to reacquaint ourselves with the conceptual outlines of evolutionary order as it has traditionally been used within LIS. On the other, it presents us with a cautionary tale about the tensions that can arise between articulating a principle of classificatory order in theory and applying that principle in practice.

\section{The North American Intellectual Background}

To understand Cutter's and Richardson's views on evolutionary order as a classificatory principle and their motivations for adopting it, it is necessary to consider the intellectual climate within which they operated. In the latter half of the $19^{\text {th }}$ century, discourse about evolution was a major current in American intellectual life. Although Charles Darwin's epochal statement of the theory of evolution in the Origin of Species had attracted little popular notice in the United States upon its initial publication there (1860), by the end of the decade, it had not only unleashed a vivid debate among scientists, clergymen, and other members of the American intelligentsia but also attracted the notice of a wider reading public (Hofstadter 1992, 13-30; Boller 1969, 1-46). The discussion around Darwin's theory played a cardinal role in leading many Americans, from the late 1860s on, to accept what one early adherent characterized as "the dynamical conception of a world in a perpetual process of evolution from one state into another" (J. Fiske, in Boller 1969, xii). However, it was not alone in doing so.

Another key impulse towards the development of an evolutionary worldview in the United States came from the English philosopher Herbert Spencer (1820-1903), who, within the framework of his Synthetic Philosophy, turned the doctrine that "matter passes from a relatively indefinite, incoherent homogeneity to a relatively definite, coherent heterogeneity" into a universal "law of evolution" that provided an explanatory key for phenomena as diverse as the formation of the solar system from the nebular mass, the embryological development of animals within the womb, the development of more complex organisms from simpler ones, and the development of larger, pluralistic societies from simpler, homogeneous ones (Copleston 1994, 128). Comprehensive in scope and optimistic in its affirmation of the inevitably progressive arc of evolutionary development, Spencer's philosophy attained immense popularity in the United States in the last quarter of the twentieth century (Hofstadter 1992, 31-35): as one commentator has put it, "[f]or middle-class Americans, Spencer was the greatest thinker of the day" (Boller 1969, 48).

In addition to being a leading authority for evolutionary philosophy, Spencer was a participant in an enterprise that drew the attention of intellectuals from all over Europe and the United States over the course of the $19^{\text {th }}$ century - the movement to classify the sciences (Miksa 1998, 34-35, 40). Spencer developed his classification of the sciences in response to that of the French positivist philosopher, Auguste Comte (1798-1857). Comte, whose ideas also had considerable impact on many $19^{\text {th }}$-century American intellectuals (Cashdollar 1976; Harp 2003), had developed a classification whose structure was based on the evolutionary principle of "filiatory order", according to which "the fundamental order of knowledge [is] one of decreasing generality and increasing complexity, and that this order [is] coincident with historical development and pedagogic sequence" (Shera 1965, 
81). Now Spencer strongly opposed Comte's classificatory logic, claiming that gradations in the level of abstraction with which a science treats phenomena should serve as the basis of classification (Eisen 1967, esp. 57-61). Despite this theoretical difference, the system of sciences that he developed corresponded to a substantial degree with the filiatory structure of Comte's system (see Table 1). Given the great cachet that Comte's and Spencer's philosophical systems enjoyed in the latter half of the $19^{\text {th }}$ century, it is unsurprising that their classifications of the sciences proved deeply influential: as Bliss $(1929,345)$ would later observe, "these two [sci., Comte and Spencer-TMD] have contributed most to establish the order of sciences now accepted in the scientific and educational consensus". The idea of evolutionary order was thus very much in the air when Cutter and Richardson were developing their own ideas of bibliothecal classification, to which we now turn.

Table 1. Sequence of Main Classes in Comte's and Spencer's Classifications of the Sciences

\begin{tabular}{|l|c|c|}
\hline Comte I (1830) & Comte II (1854) & Spencer (1864) \\
\hline Mathematics [1] & Natural Philosophy \\
Cosmology & Abstract Science \\
Astronomy [2] & Mathematics [1] & Mathematics [1] \\
\hline $\begin{array}{l}\text { Physics [3] } \\
\text { Chemistry [4] }\end{array}$ & Astronomy [2] & Abstract-Concrete Science \\
Physiology [5] & Physics [3] & Mechanics [3-4] \\
Social Physics [6] & Chemistry [4] & Physics [3] \\
& Biology [5] & Concrete Science \\
& Social Philosophy [6] & Astronomy [2] \\
& & Geology \\
& & Biology [5] \\
& & Psychology \\
& & Sociology [6] \\
\hline $\begin{array}{l}\text { For full expositions of Comte 1 and Spencer and a discussion of the underlying principles, see Comte 1988, } \\
\text { 35-67; Spencer 1878, 63-112. }\end{array}$ & \\
\hline $\begin{array}{l}\text { This table represents highly simplified versions of Comte's and Spencer's classifications of science, derived } \\
\text { from Richardson 1901, 134 \& 142. Two versions of Comte's classification are given: the first derives from his }\end{array}$ \\
\hline
\end{tabular}




\section{Cutter's Conception of Evolutionary Order}

From the late 1870s until his death in 1903, one of Cutter's major professional preoccupations was the construction of a book classification that resulted in his (partially unfinished) Expansive Classification (EC) (Miksa 1977, 57-61). In his writings on the subject, Cutter emphasized that his primary ambition was to create a classification of books, not sciences. Nevertheless, he maintained, if such book classification was to have "permanent value", its designer should "keep[] always before his mind a classification of knowledge" (Cutter 1898, 87). The initial outline of his own classification (Cutter 1879, 237) adopted an order that has been variously compared to that of Brunet (Miksa 1977, 57), that of Edwards (Grolier 1974, 63), and the inverted Baconian model (Sayers 1955, 53). Within this outline, however, certain classes, most notably those dealing with the natural sciences, followed an order broadly matching those of Comte and Spencer (see Table 2). Notably, these classes had been prepared by Richard Bliss, a librarian who was one of Cutter's closest collaborators in work on the EC throughout its development (Cutter 1879, 240, n. *; Miksa 1974, 523). Trained in the natural sciences, Bliss was an ardent advocate

Table 2: Natural Sciences in the Earliest Version of Cutter's Classification

\begin{tabular}{|c|c|}
\hline \multirow[t]{5}{*}{$\mathrm{H}$} & Natural Sciences in general \\
\hline & Mathematics, Mechanics, \\
\hline & Fysics (General, Fluids, Gases, Sound, Light, Heat, Electricity, Magnesium), \\
\hline & Chemistry, \\
\hline & Astronomy. \\
\hline \multirow[t]{4}{*}{ I } & Geology, Dynamical (Fysical geography, Fysiography) \\
\hline & Geology, Statical (Geol. Proper), incl. Mineralogy \\
\hline & Biology, \\
\hline & Microscopy. \\
\hline \multirow[t]{3}{*}{$\mathrm{J}$} & Palaeontology (General), \\
\hline & Natural History (i.e. Botany and Zoölogy together), \\
\hline & Fytology (Botany and Botanical palaeontology). \\
\hline $\mathrm{J}$ & Zoölogy and Zoölogical Palaeontology. \\
\hline \multicolumn{2}{|c|}{$\begin{array}{l}\text { This table is excerpted from Cutter } 1879,237 \text {, with original spelling. Note the close correspondence between } \\
\text { the sequence of subjects in classes H and I and the sequence of Sciences in Spencer's classification of the } \\
\text { sciences in the righthand-most column of Table } 1 \text { above. Note that preceding the natural sciences in Cutter's } \\
\text { Scheme were "Filosofical Sciences", "Historical Sciences", and "Social Sciences"; following them were } \\
\text { "Anthropology", "Medicine", "Useful Arts", "Fine Arts", "Literature", "Book Arts" and "Language". For an } \\
\text { outline of the mature, canonical version of the Expansive Classification, which does not, in its general } \\
\text { structure, differ substantially from the one described here, see Richardson 1901, 202-207; Sayers 1955, 94-95. }\end{array}$} \\
\hline
\end{tabular}


of evolutionary thought, arguing that "[t]he principle of classification which will ultimately be recognized as ruling in all departments of knowledge, as it now rules in science, is unquestionably the principle of evolution, the corner-stone of which is a progression from the homogeneous to the heterogeneous" (Bliss 1882, 104; cf. Bliss 1882, 251). Cutter's collaboration with Bliss, as well as his acquaintance with John Fiske, the well-known popularizer of Spencer's philosophy (Boller 1969, 52-53, Miksa 1974, 524), may well have encouraged him to adopt evolutionary order as the official principle for the EC. At any rate, in the later phases of its development, he asserted that "the expansive classification follows the evolutionary idea throughout", claiming this as a point of superiority over the Dewey Decimal Classification, whose sequence of classes he deemed to be less "scientific" (Cutter $1898,86 ; 1897)$.

What, then, did Cutter mean by evolutionary order? In an early article describing his classification table for the natural sciences, he described it as entailing " 'special,' 'past' before 'present,' 'dynamical' or theoretical before 'statical' or descriptive" (Cutter 1880, 166), thus invoking simultaneously gradations in degree of generality, location in time, and degree of abstractness - all criteria that, mutatis mutandis, fit well within a Comtean or Spencerian framework. In practical terms, this meant that the general sequence of classes in the natural sciences "advance[ed] from matter to life", while, within the classification of biological subjects, classes pertaining to "Fytology" (i.e., Botany) preceded those pertaining to "Zoölogy" (Cutter 1879, 238; see Table 2 above). By the same token, the subdivisions of the "Zoölogy" class "commenc[ed] with the monera and end[ed] with the primates" - a sequence that, according to Cutter, "leads ... naturally to Anthropology and Ethnology" (p. 238). In general, the order of classes for the natural sciences given in the EC was based on the classical scale of nature (i.e., mathematical entities before physical entities, inorganic entities before organic entities, plants before animals, brute animals before human beings) - an order that, mutatis mutandis, finds numerous parallels in the natural science classes of other late $19^{\text {th }}$-century bibliographical classifications. ${ }^{2}$ Unlike his fellow classificationists, however, Cutter explicitly described this sequence of classes as representing "the order of evolution" in terms of both complexity and chronology (p. 238).

Because Cutter and his contemporaries held evolution to be a basic structuring principle of the natural world, the classification of the natural sciences within EC formed an obvious and, so to speak, natural venue for the application of the principle of evolutionary order. But how did the principle fare in EC classes falling outside of the natural sciences? Cutter's collaborator Bliss $(1889,244)$ acknowledged that evolutionary order might be

2 One may compare, for example, the sequences of classes 500-590 in Dewey's Decimal Classification (1876), the subdivisions of class H in W. Swan Sonnenschein's bibliographical classification for The Best Books (1887), classes P-S in Otto Hartwig's classification at the University of Halle (1888), and classes 35-51 in the Peoria Public Library version of William Torrey Harris's book classification (1896); For tabular synopses, see Brown 1898, 56 (Sonnenschein), 58 (Hartwig), 64 (Peoria), 69 (Dewey). 
more difficult to establish for "subjects like the arts and manufactures": he claimed, nevertheless, that Cutter's "arrangement of the arts" in the EC presented "a logical and natural sequence" consonant with the principle of "development in the life history of man". Even a cursory examination of some of Cutter's showcase examples reveals, however, a notable slackening in his application of the principle. For example, he presented, as exemplars of the EC's adhesion to the principle of evolution, the fact that the sequence of classes for "the book arts follow the history of the book from its production ..., through its distribution..., to its storage and use in libraries ..., ending with its bibliography", while those for economics are based on a "natural order - population, production, distribution of the things produced, distribution of the returns, property, consumption" (Cutter 1898, 86). In these cases, it is clear that the classes are to follow a (chrono)logical order based on idealized narratives of the processes of book production and economic exchange: such sequences do not, however, express the movement from generality to speciality or from simplicity to complexity that typify evolutionary order in the strict sense of the term. In other cases, the order of classes appears to have been based less on evolutionary order than on sheer goodness of conceptual fit: thus, for example, "Ecclesiastical History" followed "Christianity" and preceded "History" not because this sequence betokened any evolutionary progression from Christianity to History via Ecclesiastical History, but because it provided a "natural" bridge between the fields of religion and history (Cutter 1897, 198; cf. already 1879, 238). In general, the notion of a "natural" order appears to have been equivocal for Cutter, encompassing both evolutionary order (i.e., a sequence of classes based on the progression from general to special, past to present, and abstract to concrete) and what might be termed "naturalized" order (i.e., a sequence of classes based on conceptual connections deemed appropriate by a classificationist in light of the cultural logic of his time).

Despite Bliss's $(1889,244)$ claim that "Mr. Cutter's classification is based upon a philosophical principle which pervades the whole of it", the EC did not reflect any single, consistently applied notion of evolutionary order: rather, sequences of classes based on the development from simplicity to complexity and the movement from generality to speciality were intermingled with sequences based on an idealized chronological order or what Cutter took to be a "natural" or "logical" order. How is this inconsistency to be explained? Part of the answer doubtless lies in Cutter's tendency to conflate evolutionary order with naturalized order, both of which could be interpreted as reflective of a "natural" order. One should, however, also consider the fundamentally practical orientation of Cutter's work. Now Cutter's $(1898,87)$ stated goal for the EC was to "provide a classification at once logical and practical". Insofar as the classification was to be "logical", it had to have a theoretical underpinning: in the case of the EC, "the evolutionary idea" was to provide this theoretical foundation (p. 86). Nevertheless, Cutter also held that a bibliographical classification ought to group its classes in such a way as "to bring together those which have a practical connection, so that when a reader is using any division of the library he would have on either hand the classes of books which he is most likely to wish to use at the same time" (Cutter 1879, 237 [emphasis mine]): this consideration, he claimed, had "a 
strong shaping influence" on his own work as a classificationist. This statement, together with Cutter's $(1898,87)$ insistence that the EC was "not intended for a classification of knowledge, but of books", indicates that his primary concern in elaborating the EC was practicality rather than theoretical self-consistency: whereas he cited the evolutionary idea as theoretical justification for the order of classes in EC, his blurring of the distinction between evolutionary order and natural(ized) order allowed him to arrange the sequence of classes in accordance with what he considered to be the most practical order for library use, even if this order did not conform to evolutionary order in the strict sense of the term. For Cutter, then, there was an inherent tension between the theoretical principles underpinning the ordering of classes within a classification of knowledge and the practical exigencies of classifying books in a library setting: the latter ultimately seems to have outweighed the former in his construction of the EC. ${ }^{3}$ As we shall see in the following section, Richardson would reach very similar conclusions.

\section{Richardson's Conception of Evolutionary Order}

Whereas Cutter discussed evolutionary order solely within the context of developing a practical bibliothecal classification, the first full-scale theoretical treatment of the topic within the library community came from the pen of Richardson (1901). According to Richardson, the "things" of the world - encompassing both material objects and ideas - are related to one another in a natural order accessible to the human mind: the goal of classification is to arrange human ideas about the world in a sequence conforming to this natural order (pp. 3-5). Since, he argued, a "science ... is nothing apart from the things or facts with which it deals", it follows that "the order of science is the order of things" (p. 19 [emphasis his]). Thus, a well-constructed classification of the sciences should seek to arrange them in accordance with the natural order of the world. Richardson maintained that such a classification should ideally follow three general laws: (1) the law of likeness, according to which "all things are organized according to their likeness"; (2) the historical law, according to which "the progress of things in time is also in general a genetic progress in complexity"; and (3) the law of evolution, according to which "the law of historical progress from the simple to the complex holds good of all things which tend toward continued existence" (p. 15). This final law, Richardson noted, combined within itself the notions of "logical progress in complexity", "progress in space and time corresponding with progress in complexity", and "the genesis of the more from the less complex" (p. 15). All this formed the basis for Richardson's definition of "evolutionary classification" as "classification according to the order of likeness from the simplest to the most complex" (p. 11) and it was in accordance with these three laws that he constructed a theoretical order of

\footnotetext{
3 This interpretation is congruent with Miksa's $(1998,37)$ suggestion that Cutter's invocation of evolution as the guiding principle of the EC had less to do with the goal of creating a theoretically well-grounded classification than it did with a desire to legitimate his system, and so render it more appealing to his contemporaries, by associating it with a widely accepted and prestigious scientific theory (cf., however, Miksa 1974, 524-525).
} 
the sciences, whose general resemblance to the schemes of Comte and Spencer is unmistakable (see Table 3, left-hand column, below).

Based on a clearly defined idea of evolutionary order as a historical progression from simple to complex things and supported by a well-constructed correlation of that progression to the various disciplines, Richardson's classification of the sciences was highly regarded by fellow library theoreticians; even the notoriously critical Bliss (1929, 400) deemed it "almost correct". Yet, paradoxically enough, having carefully put together this theoretical classification, Richardson went on to dismantle it in the arena of practice.

Like Cutter, Richardson distinguished between the theoretical classification of the sciences and the practical classification of books. On one level, he saw no solution of continuity between these two types of classification, claiming that "theoretical and practical classification are absolutely alike in their principles" (Richardson 1901, 69). Yet, he argued, while theoretical and practical classification are based on common principles, they differ in fundamental ways:

[t]he classification or order of things is nature and is not a human creation. The classification or order of ideas follows the order of this classification of things and is science. The classification of books, on the other hand, is an art-a human creation for a human end (p. 49).

Whereas, in Richardson's view, the order of classes in a theoretical classification of the sciences should seek to mirror the order of nature and the order of ideas as closely as possible, a practical classification of bibliographic material should aim not at a scientific representation of our knowledge of the world but at fostering "economy and increased efficiency in the use of books" by "getting together the books most used together" (p. 58). Because "use is the watchword of book-classification", it followed that, if there should happen to be a conflict between the theoretical order of sciences and the practical exigencies of library classification, the former must yield to the latter (p. 58).

Richardson identified a number of ways in which a library classification might deviate from the theoretical ideal of evolutionary order. Some deviations were justified on purely practical grounds: for instance, he argued, it is legitimate to modify the ideal evolutionary order of classes in a bibliographical classification "by the law of putting together the books most used together" (p. 78) - a rationale of collocation based on user expectations and habits akin to that of Cutter. Other arguments for departing from the ideal of evolutionary order had their basis in philosophical, as well as practical, considerations. For example, Richardson held that 
Table 3. Richardson's Theoretical Classification of the Sciences and Practical Book Classification for the Princeton Library

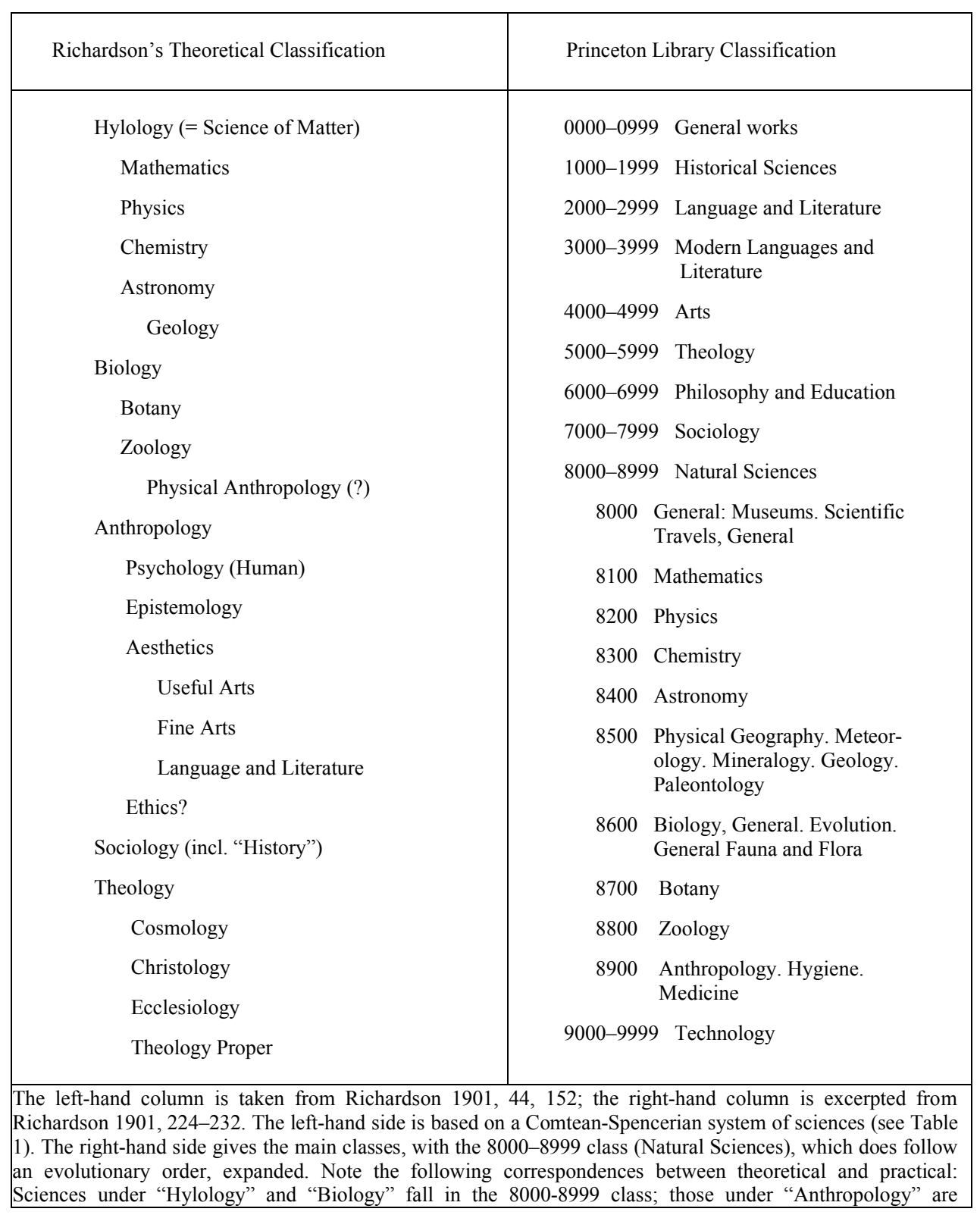


distributed into the 2000-4999 and 6000-6999 classes; "Sociology" is divided between the 1000-1999 and 7000-7999 class; and "Theology" falls in 5000-5999. Clearly, the evolutionary order of the theoretical classification has been largely abandoned in the main class structure of the practical classification.

[t] he order of things and the corresponding order of sciences follow naturally in their statement the order of progress from the simple to the complex, from the like to the like and unlike, from the less various, therefore, to the more various, from the less to the more inclusive. ${ }^{4}$

The classification of books on the other hand does not in the first instance follow the historical order or order of complexity, but the inverse evolutionary order, the more to the less inclusive, ${ }^{5}$ the unlike to the like (p. 72).

Richardson presented two arguments for preferring an inverted evolutionary order in library classifications. First, such an order dovetailed nicely with the general intuition among librarians that "the most complex books containing the greatest variety of subjects should precede instead follow their inclusive subdivisions" (p. 66; cf. p. 73) and so constituted a neat codification of the common practice of having multi-subject reference works precede monographs in the classification schedule. Second, in Richardson's view, inverted evolutionary order "follows ... the order in which the human mind proceeds in tracing out the order of things": an arrangement of books in accordance with this sequence would thus

\footnotetext{
Note that in this passage, Richardson extends his definition of evolutionary order first by claiming to derive a sequence "from the less various to the more various" from an application of his law of likeness ("from the like to the like and unlike") and then correlating to this sequence one that moves "from the less to the more inclusive". The first part of this move is readily comprehensible: after all, the very act of differentiation implied by the law of likeness cannot but betoken a movement from the less various ("the like") to the more various ("the like and unlike"). The second part, on the other hand, is quite problematic. Richardson (1901, p. 86) appears to understand inclusivity as a corollary of variability: the greater the variability of objects comprehended in a class, the more inclusive that class is. This is evident in a passage in which Richardson discusses the ordering of books according to the gradation of inclusivity of their subjects: "if we were following the order from the less to the more inclusive we would place, say first treatises on individual animals, then treatises on a class of animals, then treatises on all animals, then on all living things, then on all things living and lifeless" (p. 73). From a logical point of view, however, there is no warrant for stipulating that evolutionary order should begin with individuals and then proceed to ever more inclusive classes, for this in no way follows the laws of likeness, history, and evolution that Richardson had taken as the theoretical basis for his classification of things and ideas. The most likely explanation for Richardson's move is that he viewed the movement from lesser to greater inclusion in terms of bibliographical subjects, on the assumption that "the most complex books contain[] the greatest variety of subjects" (p. 66) and that the greater the variety of subjects in a book, the more general (i.e., inclusive) the subject class to which that book is to be assigned: on this interpretation, the sequence from less inclusive to more inclusive would be a corollary of the sequence from simple to complex as well as a corollary of the sequence from like to unlike. This line of reasoning, however, seems to confuse a gradation in complexity based on things in general (i.e., the sequence from simple to complex founded on the historical and evolutionary laws) and a gradation in complexity based on a particular type of thing, namely the subject content of books (i.e., the sequence from lesser to greater inclusivity), and so constitutes a decidedly weak point in Richardson's attempt to extend the definition of evolutionary order.

5 One should observe that the movement from "the more to the less inclusive" in Richardson's inverted evolutionary order is tantamount to the movement from "general to special" that Cutter $(1880,166)$ took to be one of the dimensions of evolutionary order. In this regard, Cutter's understanding of evolutionary order was closer to Bliss's principle of gradation by speciality than Richardson's was.
} 
be more congruent with what he took to be the basic human cognitive expectation that "the whole should precede the parts" (pp. 72-73). As a consequence, he recommended that, in practice, library classifications favor inverted evolutionary order and make only sparing use of the sequence of evolutionary order (pp. 66, 73-74).

For Richardson, no less than Cutter, there was thus an essential tension between theoretical and practical classificatory order: the evolutionary order of the former served as an ideal norm for class sequence but was subject, in practice, to a number of modifications in the latter. Richardson (1901, p. 86) insisted that such modifications did not detract from the theoretical integrity of practical bibliothecal classifications: "the theoretical order is yet the rule, however many exceptions there may be" (p. 86). Nevertheless, a comparison of his theoretical system of the sciences with the practical classification that he designed for the Princeton University Libraries dramatically shows to what degree a large number of exceptions could efface, in practice, the putative theoretical order of evolution (see Table 3, above).

\section{Cutter and Richardson on Evolutionary Order: A Mixed Legacy}

Cutter and Richardson were pioneers in introducing, each in his own way, the concepts of evolution and evolutionary order into the discourse of library classification theory. The legacy they left behind was a mixed one, rife with theoretical promise, yet hedged with limitations in practice. At their best, Cutter's and Richardson's definitions of evolutionary order as encompassing simultaneously the conceptual gradations from general to special (Cutter), from simple to complex (Cutter \& Richardson), and from past to present (Cutter \& Richardson) offered clear and analytic summations of a complex concept on which later theorists, such as Sayers (e.g., 1915, 28-29) and Bliss would build. Furthermore, their advocacy of the concept of evolutionary order as an ideal theoretical order rooted in natural history doubtless helped to reinforce the philosophical tendency towards realism in early library classification theory (Hjørland 2004, 499) - a tendency that is re-emerging among advocates of evolution-based classification today (e.g., Gnoli 2004).

Although Cutter's and Richardson's discussion and endorsement of evolutionary order was a lasting contribution to LIS discourse(s) on classification, their respective treatments of it proved problematic in certain respects. One source of difficulty - especially manifest in the case of Cutter - was a tendency to use the principle to characterize sequences of classes that were not, strictly speaking, evolutionary in nature. As we have seen, Cutter tended to conflate evolutionary order with what he took to be natural order in the chronological progression of processes or in the naturalized "logical" relationship between subject areas: this allowed him to claim that the whole of the EC was pervaded by the evolutionary principle whereas, in fact, only some sections of the classification actually reflected evolutionary order in the way that he had formally defined it. A more systematic difficulty in applying the notion of evolutionary order consistently lay in Cutter's and Richardson's insistence on the distinction between theoretical and practical classification. Although claiming that bibliothecal classifications must be based on theoretical principles such as evolutionary theory, both men went on to argue that such classifications were 
practical classifications and, thus, that practical considerations should outweigh theoretical purity in establishing the sequence of their classes: this line of argument provided warrant for practical deviation from the ideal norm of evolutionary order. Such limitations to the consistent application of evolutionary order were doubtless reinforced by the structural constraints of the enumerative classification model and the discipline-based approach within which both Cutter and Richardson operated.

Cutter's and Richardson's failure to create bibliothecal classifications truly based on evolutionary order was due both to a certain tendency on their part to play fast and loose with the concept in practice and to the limitations of the classificatory framework within which they worked: it should thus not be taken as evidence for the impracticability of evolutionary order as an ordering principle. Many of the problems that they encountered can be resolved by more rigorous adherence to one's stipulated definition of evolution and by the adoption of more flexible approaches to classification, such as faceting, that render the crippling distinction between "theoretical" and "practical" classification moot. Yet even the adoption of such methodological improvements does not assure success in applying evolutionary order to bibliographic classifications: even the CRG, employing a faceted, phenomenon-based approach, found it difficult to apply it, as embodied in integrative levels, consistently, especially with regard to the realm of social and cultural entities (Spiteri 1995) - a problem reminiscent of Cutter's experience with the EC. It remains to be seen whether current efforts can overcome such difficulties or whether general bibliographic classifications exhibiting a consistent evolutionary order are to remain a compelling, but unattainable, theoretical dream.

\section{Acknowledgements}

I thank Claudio Gnoli, Miloslava K. Dousa, and two anonymous reviewers for their helpful comments on an earlier draft of this essay. It goes without saying that I alone am responsible for any errors of fact or infelicities in interpretation or exposition that may remain.

\section{References}

Bliss, H. E. (1929). The organization of knowledge and the system of sciences. New York: Henry Holt \& Co.

Bliss, R., (1882a). Alfabetization versus classification. Library Journal, 7, 104-105.

Bliss, R. (1882b). Logical classification. Library Journal, 7, 251.

Bliss, R. (1889). Report on classification. Library Journal, 14, 240-246.

Boller, P. F., Jr. (1969). American thought in transition: the impact of evolutionary naturalism, 1865-1990. Chicago: Rand MacNally.

Broughton, V. (2008). Henry Evelyn Bliss - the other immortal, or a prophet without honour? Journal of Librarianship and Information Science, 40(1), 45-58.

Brown, J. D. (1898). Manual of library classification and shelf arrangement. London: Library Supply Company. 
Cashdollar, C. D. (1976). European positivism and the American Unitarians, Church History, 45, 490-506.

Comte, A. (1988). Introduction to positive philosophy (F. Ferré, ed. \& trans.). Indianapolis: Hackett.

Copleston, F. (1994). A history of philosophy, vol. VIII. Modern philosophy: empiricism, idealism, and pragmatism in Britain and America. New York: Doubleday.

Cutter, C. A. (1879). Classification on the shelves: with some account of the new scheme prepared for the Boston Athenaeum. Library Journal, 4, 234-243.

Cutter, C. A. (1880). A classification for the natural sciences. Library Journal, 5, 163-166.

Cutter, C. A. (1897). Reasons for using the "Expansive Classification" in an international bibliography. Bulletin de l'Institut International de Bibliographie, 2, 196-199.

Cutter, C. A. (1898). The expansive classification. In Transactions and Proceedings of the Second International Library Conference held in London, July 13-16, 1897 (pp. 8488). London: Printed for Members of the Conference.

Edwards, E. (1859). Memoirs of libraries including a handbook of library economy (2 vols.). London: Trübner \& Co.

Eisen, S. (1967). Herbert Spencer and the spectre of Comte. The Journal of British Studies, $7(1), 48-67$.

Foskett, D. J. (1978). The theory of integrative levels and its relevance to the design of information systems. Aslib Proceedings, 30(6), 202-208.

Gnoli, C. (2004). Naturalism vs. pragmatism in knowledge organization. In I. C. McIlwaine (ed.), Knowledge Organization and the Global Information Society: Proceedings of the Eighth International ISKO Conference, 13-16 July 2004, London, UK (pp. 263-268). Würzburg, Germany: Ergon Verlag.

Gnoli, C. (2006). Phylogenetic classification. Knowledge Organization, 33(3), 138-152.

Gnoli, C. (2008). Categories and facets in integrative levels. Axiomathes, 18(2), 177-192.

Gnoli, C. (2008- ). Integrative Level Classification: a general, interdisciplinary, phylogenetic, freely faceted knowledge organization system. Retrieved, May 10, 2009, in http://www.iskoi.org /ilc/book/

Gnoli, C., \& Poli, R. (2004). Levels of reality and levels of representation. Knowledge Organization, 31(3), 151-160.

Grolier, E. de (1974). Le système des sciences et l'évolution du savoir. In J. A. Wojciechowski (ed.), Conceptual basis of the classification of knowledge: Proceedings of the Ottawa Conference on the Conceptual Basis of the Classification of Knowledge, October $1^{\text {st }}$ to $5^{\text {th }}, 1971$ (pp. 20-118). Pullach bei Münich: Verlag Dokumentation.

Harp, G. J. (2003). Positivism. In S. I. Kutler (ed.), Dictionary of American history, Vol. 6 ( ${ }^{\text {rd }}$ ed.; pp. 423-425). New York: Charles Scribner's Sons.

Hjørland, B. (2004). Arguments for philosophical realism in library and information science. Library Trends, 52(3), 488-506.

Hofstadter, R. (1992). Social Darwinism in American thought. Boston: Beacon Press. 
LaMontagne, L. E. (1952). Historical background of classification. In M. F. Tauber (ed.), The subject analysis of library materials (pp. 16-28). New York: Columbia University, School of Library Service.

Lesley, J. P. (1863). On the classification of books. Annual report of the Board of Regents of the Smithsonian Institution, showing the operations, expenditures, and condition of the institution for the year 1862 (pp. 416-425). Washington: Government Printing Office.

Maltby, A. (1975). Sayers' manual of classification for librarians $\left(5^{\text {th }}\right.$ ed.). London: André Deutsch.

Merlin, R. (1915). Classification of works into catalogues: [Paper] I. In Proceedings of the Librarians' Convention held in New York City, September 15, 16, and 17, 1853 (pp. 4549). Cedar Rapids, IA: The Torch Press. [Originally published in Norton's Literary and Educational Register for 1854, 1854, pp. 81-84.]

Miksa, F. L. (1974). Charles Ammi Cutter: Nineteenth-century systematizer of libraries. Unpublished doctoral dissertation, Graduate Library School, The University of Chicago.

Miksa, F. L. (ed.) (1977). Charles Ammi Cutter, library systematizer. Littleton, CO: Libraries Unlimited.

Miksa, F. L. (1998). The DDC, the universe of knowledge, and the post-modern library. Albany, NY: Forest Press.

Mills, J., \& Broughton, V. (1977). Bliss bibliographical classification, second edition: Introduction and auxiliary schedules. London/Boston: Butterworths.

Ranganathan, S. R. (1967). Prolegomena to library classification (3 ${ }^{\text {rd }}$ ed.). Bombay: Asia Publishing House.

Richardson, E. C. (1901). Classification: theoretical and practical. New York: Charles Scribner's Sons.

Sayers, W. E. B. (1915). Canons of classification applied to "the subject", "the expansive", "the decimal", and "the Library of Congress" classifications: A study of bibliographical classification method. London: Grafton \& Co.

Sayers, W. E. B. (1955). An introduction to library classification: Theoretical, historical and practical $\left(9^{\text {th }}\right.$ ed.). London: Grafton \& Co.

Shera, J. H. (1965). Libraries and the organization of knowledge. Hamden, CT: Archon Books.

Spencer, H. (1878). Recent discussions in science, philosophy, and morals (new and revised ed.). New York: D. Appleton \& Co.

Spiteri, L. (1995). The Classification Research Group and the theory of integrative levels. Katharine Sharp Review, 1. Retrieved March 9, 2009, from http://mirrored.ukoln. ac.uk.proxy2.library.uiuc.edu/lis-journals/review/review/summer1995/spiteri.pdf 